\title{
Família na visão dos psicólogos do CRAS
}

\section{Family from the point of view of CRAS psychologists}

\author{
Juliana Marion (orcid.org/0000-0003-3510-9965)' \\ Caroline Rubin Rossato Pereira (orcid.org/0000-0001-9861-8391)2
}

\begin{abstract}
Resumo
Este estudo buscou investigar as concepções de família de psicólogos dos Centros de Referência de Assistência Social (CRAS). Para isso, foram realizadas entrevistas individuais com cinco psicólogos inseridos nos CRAS de uma cidade do Rio Grande do Sul, a fim de acessar suas crenças, valores e representações envolvendo o conceito de família. A partir da análise qualitativa de conteúdo, os resultados indicaram que os participantes consideraram família as pessoas que estabelecem relações a partir de laços afetivos, não restringindo sua definição à consanguinidade. Ainda, apontaram como indicadores de saúde familiar a capacidade de cuidar dos filhos, manejar conflitos e a não violência. Todavia, alguns participantes apresentaram resquícios de uma visão de família tradicional e romantizada. Ressalta-se a importância de a atuação do psicólogo estar atrelada à capacidade de analisar criticamente o contexto de atuação e a realidade social brasileira. A partir disso, espera-se contribuir para a construção de uma prática que não reproduza a violência social e a estigmatização das famílias atendidas.
\end{abstract}

Palavras-chave: Família. Assistência social. Psicologia.

\begin{abstract}
This study sought to investigate the family conceptions of psychologists at the Social Assistance Reference Centers (CRAS). For this, individual interviews were conducted with five psychologists inserted in the CRAS of a city of Rio Grande do Sul, in order to access their beliefs, values and representations involving the concept of family. From the qualitative analysis of content, the results indicated that the participants considered family the persons who establish relationships based on emotional ties, not restricting their definition to consanguinity. In addition, they pointed out as indicators of family health the ability to take care for children, handle conflicts and non-violence. However, some participants presented traces of a traditional and romanticized family view. The importance of the psychologist's performance is linked to the ability to critically analyze the context of practice and the Brazilian social reality. From this, it is expected to contribute to the construction of a practice that does not reproduce social violence and stigmatization of the families served.
\end{abstract}

\footnotetext{
${ }^{1}$ Universidade Federal de Santa Maria, Santa Maria, Brasil. E-mail: julianamarion@live.com.

2 Universidade Federal de Santa Maria, Santa Maria, Brasil. E-mail: carolinerrp@gmail.com.
} 
Keywords: Family. Social assistance. Psychology.

"Família" não deve ser concebida como um conceito homogêneo, visto que é possível identificar e descrever diversas configurações, maneiras de se organizar e se relacionar, influenciadas por fatores ambientais, sociais, econômicos, culturais, políticos e religiosos. Assim, a família se altera conforme a época e a forma com que esses fatores estão estruturados em um determinado contexto histórico e cultural (Osorio, 2002).

Em seus termos mais básicos, a família se constitui como responsável por garantir a sobrevivência biológica de seus membros. Além dessa função, ela também é a principal fonte de suporte para o desenvolvimento biopsicossocial e deve facilitar o processo de aprendizagem, favorecendo o desenvolvimento cognitivo e as trocas com o mundo. Em seu meio são estabelecidos quatro tipos de relações pessoais: a aliança (casal), a filiação (pais/filhos), a consanguinidade (irmãos) (Osorio, 2002) e a convivência (Moreira, 2013). Através dessas relações são transmitidos valores éticos, estéticos, religiosos e culturais, e também fornecidas condições para o sujeito desenvolver sua identidade pessoal (Osorio, 2002). Ainda, a importância da família não está restrita apenas aos membros do núcleo doméstico. Mesmo que essa seja a organização que predomina em nossa sociedade, considera-se que cada núcleo seja um subsistema emocional, que se mantém associado às relações passadas, presentes e futuras, englobado em um sistema familiar maior (Carter \& McGoldrick, 1995).

Definir o que é "família" constitui uma tarefa complexa por exigir a análise do entendimento tradicional de família e dos fatores envolvidos nesse conceito (Settles, 1999). Das famílias matriarcais comunitárias dos povos nômades à sua organização patriarcal, encontram-se funções familiares bem definidas e delimitadas entre homens e mulheres. Apesar da criação das crianças ser reservada à figura feminina em ambos os sistemas sociais, com o patriarcado suprimiu-se o tom colaborativo da divisão de tarefas, tornando o homem o chefe da família. Nessa organização social, a família passou a ter como característica de suas relações a possessividade e o poder, de modo que a mulher devia obediência ao homem e as crianças deviam obedecer inquestionavelmente aos adultos 
(Osorio, 2002). Assim, a configuração familiar patriarcal, designada também como "tradicional", tomou como base principal a transmissão de patrimônio por descendência e a autoridade patriarcal.

Entre os séculos XVIII e XX, a família, então nuclear, incorporou uma lógica mais afetiva e recíproca em suas relações, formando-se a partir da união de duas pessoas dispostas a estabelecerem relações íntimas, além de prezar pela divisão das atividades domésticas e tarefas familiares entre os cônjuges. Com essa transição, a autoridade no seio familiar se tornou complexa, acompanhada de um aumento na frequência de separações e recasamentos (Roudinesco, 2003).

Esse modelo familiar nuclear prevaleceu até a década de 1960, quando a divisão e hierarquia dos papéis de gênero foram questionadas e emergiram famílias que incorporaram essa nova ideologia no relacionamento conjugal, tornando-se um núcleo de afeto e proteção, escolhido através de sentimentos recíprocos das pessoas envolvidas (Souza \& Ramires, 2006). Considera-se, de acordo com Arrazola (1997), que a concepção de gênero possui papel importante na estruturação e na organização da forma como homens e mulheres se relacionam entre $\mathrm{si}$, inserem-se na sociedade e executam suas atividades (Arrazola, 1997). Essas concepções dos papéis diferenciados de gênero são transmitidas e mantidas socialmente através de diversos meios e em diversos contextos de vida, pelas famílias, escola, mídia, literatura, cinema, entre outros (Meyer, 2003). Assim, a partir do final do século XX, com as mudanças, principalmente, no papel feminino, e com o incremento nas taxas de divórcio e recasamento, a família contemporânea assumiu um modelo de união que tem como premissa o vínculo afetivo, a proteção e o desenvolvimento dos seus membros, fonte de solidariedade e compartilhamento de recursos para sobrevivência (Instituto Brasileiro de Geografia e Estatística [IBGE], 2010).

Hoje, relações conjugais são mantidas por homens e mulheres, com o sexo oposto ou com o mesmo sexo, pais e mães solteiros com filhos, através de laços sexuais e afetivos que impulsionam o desejo de compartilhar uma vida, estando ligados ou não ao casamento civil ou religioso e à procriação (Osorio, 2002). O casamento deixou de ser um contrato de indissolubilidade familiar mediado pelo divino e estabeleceu-se como um acordo baseado na liberdade e no amor entre duas pessoas. Da mesma forma, a parentalidade, até então 
diretamente relacionada ao casamento e à função biológica, deixa de ser inevitável ou a finalidade da união entre duas pessoas (Kehl, 2003).

Contudo, o ideal de família nuclear composta por pai, mãe e filhos residindo na mesma casa ainda se faz presente no imaginário social. Termos utilizados para designar as configurações familiares, como "família intacta", correspondente à família nuclear com filhos biológicos, usado em oposição à concepção de "famílias desestruturadas", "recompostas" ou "não-tradicionais"; deixam transparecer a suposição de que existe uma configuração familiar considerada mais "correta". Isso se apoia em uma noção presente no senso comum de que a configuração nuclear seria mais adequada ao desenvolvimento saudável de seus integrantes, noção que não encontra respaldo na literatura científica, uma vez que não existe associação entre a composição familiar e dificuldades emocionais dos filhos a longo prazo (Souza \& Ramires, 2006).

Sobre isso, ressalta-se que o valor da família se dá a partir da qualidade das relações estabelecidas entre os seus membros, o que pode ser entendido pela presença de afeto e cuidado entre eles, independentemente de sua configuração. Além disso, no cenário brasileiro atual, a família nuclear deixou de compor a maioria dos domicílios, ocupando 49,4\% dos lares no censo de 2010 (IBGE, 2010).

Ainda, por possuir caráter social, o conceito "família" pode ser entendido como um sistema sociocultural adaptativo, que age de acordo com suas condições externas e internas, como os padrões culturais, relações sociais e afetivas, a subjetividade dos envolvidos e a interação entre esses fatores. Em virtude disso, ressalta-se que as modificações dos modelos familiares podem se manifestar de maneira heterogênea nos diferentes contextos sociais brasileiros, sendo possível a coexistência de padrões tradicionais e contemporâneos de família entre as regiões e entre as diferentes classes sociais (Koller, Antoni, \& Carpena, 2012; Peres, 2001; Trad, 2010).

No Brasil, país de contrastes socioeconômicos, cada grupo social possui um modo de vida, de práticas e de representações que fazem sentido em seu contexto (Celia, 2013), o que torna possível existir um distanciamento entre a cultura do profissional que atua no contexto do Sistema Único de Assistência Social (SUAS) e a da população atendida. Essa ideia elucida a relevância de sustentar a atuação no conhecimento da realidade das famílias e da 
comunidade, tornando o reconhecimento das demandas da população essencial para planejar intervenções adequadas e efetivas.

A realização de visitas domiciliares, a adoção da matricialidade sociofamiliar e da territorialização nas intervenções, previstas pela Política Nacional de Assistência Social (Brasil, 2004), colaboram para esse conhecimento do território e da realidade das famílias. A matricialidade sociofamiliar e a territorialização podem ser concebidas como os eixos bases das intervenções no SUAS e referem-se, respectivamente, ao fato de colocar a família e suas especificidades como foco das intervenções e considerar as características do território como centrais na compreensão das vulnerabilidades e riscos sociais da população assistida (Brasil, 2009). Assim, a família é posta como "centro do debate político, enquanto públicoalvo de políticas públicas, especialmente nos programas de transferência de renda, que objetivam o combate à pobreza e à erradicação da miséria" (IBGE, 2010, p. 63). No entanto, esses eixos, que devem servir para o desenvolvimento de práticas efetivas, podem vir a contribuir para uma prática culpabilizante desses sujeitos ao visualizar a realidade local sem considerar o complexo contexto de desigualdade social à que essas famílias estão expostas (Senra, 2014).

A atuação do psicólogo precisa estar de acordo com os princípios técnicos, éticos e científicos da Psicologia e com as orientações de trabalho da Política Nacional de Assistência Social (Brasil, 2004). Além do Código de Ética da profissão, os psicólogos podem buscar referências para a prática no Centro de Referências Técnicas em Psicologia e Políticas Públicas (CREPOP, 2008) e nos Parâmetros para a Atuação de Assistentes Sociais e Psicólogos na Política de Assistência Social (Conselho Federal de Psicologia \& Conselho Federal de Serviço Social, 2007), documentos que servem como guia ético, político e profissional do trabalho no SUAS (Coutinho \& Merigo, 2010). Sobre isso, é essencial considerar que, por mais que seja notável a preocupação com o lançamento de guias para a atuação do psicólogo na Assistência Social, isso por si só não garante que a prática venha a ser desenvolvida, efetivamente, de acordo com as orientações estabelecidas. Assim, reforçase a necessidade de conhecer a maneira pela qual os profissionais têm se adequado a essa nova demanda da profissão (Senra \& Guzzo, 2012). 
Por compreender que cada psicólogo é, além de profissional, um ser humano constituído a partir dos valores passados por aqueles que se ocuparam de seu cuidado e educação (Osorio, 2002), faz-se pertinente conhecer e discutir suas concepções de família. Assim, em conjunto com a faceta teórico-prática, as experiências de vida pessoal e profissional constituem elementos postos em ação nos momentos de "leitura" das famílias atendidas pelo Centro de Referência de Assistência Social (CRAS) e do contexto de atuação, de vinculação com o público-alvo da política e de planejamento e execução das ações na assistência social (Santos, 2014). Como sinalizado por lamamoto (2007), ao atuar no campo da assistência social, o profissional pode ocupar o lugar de propagador da moral das classes dominantes sobre a família, sendo a família foco central da política. Desse modo, como salienta Sarti (2010), o profissional precisa ser capaz de escutar as dificuldades e as potencialidades familiares para além de um modelo idealizado de família, reconhecendo em seus membros o saber sobre a sua própria realidade para, com isso, construir intervenções que o entrelacem ao saber da psicologia.

Levando em consideração as diversas configurações familiares existentes, a possibilidade de distanciamento sociocultural entre o psicólogo e a população atendida nos CRAS (Santos, 2014) e o fato de que o serviço prestado constitui a porta de entrada da proteção social básica, através da qual as famílias podem ter acesso aos programas assistenciais, o presente estudo teve como objetivo investigar as concepções de família de psicólogos que atuam nos CRAS de uma cidade do Rio Grande do Sul.

\section{Método}

\section{Participantes}

Participaram da presente pesquisa cinco psicólogos integrantes das equipes dos CRAS de uma cidade do Rio Grande do Sul, sendo este o número total de profissionais da psicologia vinculados aos CRAS do município no período da realização da pesquisa. Durante o período de coleta de dados, os participantes estavam formados há, no mínimo, seis meses, e, no máximo, nove anos, resultando em uma média de cinco anos e nove meses desde a conclusão da graduação. Em relação ao tempo de atuação no serviço, o mínimo foi de um 
mês, e o máximo de um ano, ou seja, uma média de cinco meses alocados no CRAS. Com relação ao vínculo empregatício dos psicólogos, um era concursado e os demais atuando sob regime de contrato temporário com duração de um ano.

\section{Tabela 1}

Características dos psicólogos participantes

\begin{tabular}{lll}
\hline Psicólogo & Tempo de formado & Tempo de atuação CRAS \\
\hline P1 & 9 anos & 5 meses \\
P2 & 7 anos & 1 ano \\
P3 & 6 meses & 1 mês \\
P4 & 5 anos & 4 meses \\
P5 & 8 anos & 3 meses \\
\hline
\end{tabular}

\section{Delineamento e procedimentos}

Este estudo se refere a uma pesquisa exploratória de cunho qualitativo. Seu caráter qualitativo se dá em função de procurar compreender crenças e valores dos psicólogos que atuam no CRAS. Ainda, pode ser classificada como exploratória por pretender conhecer, através das experiências dos participantes, um fenômeno e, com isso, produzir conhecimento científico (Minayo, 2013 ).

No que tange aos procedimentos de pesquisa, após aprovação do projeto pelo Comitê de Ética em Pesquisa com Seres Humanos da Universidade Federal de Santa Maria, através de contato telefônico com a Secretaria de Município de Desenvolvimento Social, foi realizado o levantamento dos CRAS da cidade onde a pesquisa seria realizada e dos psicólogos que compunham a equipe desses serviços. Na sequência, os profissionais foram contatados através do telefone do serviço para que o estudo pudesse ser explicado e fosse feito o convite de participação. Nesse contato telefônico foi agendado o encontro para a realização das entrevistas, que ocorreram individualmente nos próprios CRAS ou nas dependências da Universidade Federal de Santa Maria, de acordo com a disponibilidade do serviço e dos profissionais. 


\section{Instrumentos}

\section{Entrevistas}

Para coletar as informações, foi utilizado um roteiro de entrevista semiestruturado, que incluiu como tópicos-guia a concepção de família dos psicólogos do CRAS e a configuração e estrutura familiar dos próprios psicólogos em seu contexto social (informações complementares utilizadas como pano de fundo para análise dos dados).

\section{Considerações éticas}

A presente pesquisa foi submetida e aprovada por um Comitê de Ética em Pesquisa com Seres Humanos (CAAE 45516515.5.0000.5346). Ainda, conforme previsto na resolução 510/2016 do Conselho Nacional de Saúde (Brasil, 2016), todos os participantes assinaram o Termo de Consentimento Livre e Esclarecido. A importância desse documento está em conter as principais explicações sobre a pesquisa, sobre os direitos dos participantes e também sobre os possíveis riscos e benefícios de sua participação.

Ressalta-se que o presente estudo foi considerado de riscos mínimos segundo a Resolução 016/2000 do Conselho Federal de Psicologia, visto que não expôs os participantes a riscos maiores do que os encontrados nas atividades cotidianas. Além disso, os participantes podiam abandonar o estudo no momento que desejassem, sem que isso Ihes ocasionasse qualquer tipo de prejuízo. Considera-se que a participação no estudo possibilitou aos psicólogos o benefício de refletir acerca de suas concepções de "família" e, consequentemente, acerca do público atendido e de sua prática profissional no contexto do CRAS/SUAS.

\section{Análise dos dados}

Os dados coletados foram analisados a partir do método de análise de conteúdo, o qual pressupõe o reconhecimento da significação dessas informações. Utilizou-se o modelo 
de tipo aberto, que propõe a criação de categorias analíticas a posteriori, ou seja, após a coleta dos dados. As categorias foram definidas a partir da análise temática dos conteúdos das falas dos participantes, agrupadas por temas os fragmentos com sentidos semelhantes, de acordo com sua repetição ou relevância (Bardin, 1979; Minayo, 2013).

\section{Resultados e discussão}

A análise das entrevistas com os psicólogos indicou a presença de três categorias temáticas. A primeira, "O que é ser família?", aborda as características que os psicólogos mencionaram como delimitadoras de família, ou seja, que peculiaridades transformam um grupo de pessoas em família, juntamente com a função da família extensa, filhos e amigos. A categoria "Os papéis parentais" ilustra as concepções dos psicólogos sobre o que consideram como características necessárias em um pai e uma mãe. Já a terceira categoria, "Indicadores de saúde familiar", contempla o que os participantes consideraram como os aspectos indicativos de saúde ou adoecimento do sistema familiar.

\section{O que é ser família?}

De maneira geral, todos os profissionais indicaram em suas falas a importância do vínculo afetivo para a constituição de uma família e a segurança emocional que proporciona aos membros desse sistema. Assim, a qualidade das relações estabelecidas entre os integrantes foi posta como o elemento central, assumindo a posição que outrora a consanguinidade ou a coabitação ocupou.

Eu acho que família é isso, tu poder se dar bem com as pessoas que compõem o teu círculo familiar e, e participar de tudo, assim, das coisas boas, das coisas ruins. (P5) Eu penso em duas coisas diferentes, assim, uma sendo mais essa coisa de família sanguínea e tal e outra como relações afetivas próximas. (P2)

A família não é tu dizer que tu é minha mãe, que tu é meu pai. Pode ser o primo, pode ser não sei o que, mas é tu se ajudar, é tu ser companheiro, é tu saber que tu vai ter um suporte. (P3) 
O foco de "ser família" para os psicólogos entrevistados estava muito mais colocado no cuidado que as pessoas do sistema familiar possuem umas com as outras do que na vinculação sanguínea e desempenho rígido dos papéis familiares. Esses resultados vão ao encontro da literatura que estabelece as trocas afetivas recíprocas como fundamentais para o desempenho dos papéis familiares, em vez de relações de poder e submissão (Osorio, 2002; Roudinesco, 2003; Trad, 2010).

Além disso, Carter e McGoldrick (1995) ressaltaram que a importância da família não pode ser entendida como restrita às interações entre os membros do núcleo doméstico. Primeiramente, destaca-se que esse sistema é atravessado por dinâmicas intrageracionais (passadas, presentes e futuras), englobando nas suas relações, mesmo que de forma indireta, a família extensa. Segundo, reconheceu-se que não apenas o laço sanguíneo proporciona cuidado, proteção e segurança, funções reconhecidas como familiares e que oferecem suporte para o desenvolvimento biopsicossocial do sujeito (Osorio, 2002). Seguindo essa linha de pensamento, P3, ao referir-se aos amigos, pontuou: "Não deixa de ser uma outra família, só que não é de sangue" (P3).

Com isso, compreende-se que também esses amigos podem ser considerados família, visto que são pessoas com quem é possível estabelecer trocas de suporte social. Se a família é responsável por transmitir valores éticos, estéticos, religiosos e culturais aos seus membros, como ressaltou Osorio (2002), considera-se que as diversas relações e encontros com outros sujeitos no decorrer da vida influenciam esses valores. Assim, entende-se que toda relação afetiva pode auxiliar no desenvolvimento de uma identidade pessoal e na individuação de um sujeito. Para além da vinculação afetiva, então, a especificidade do laço familiar estaria no convívio e no cuidado estabelecido entre os sujeitos.

Da mesma forma, a família extensa foi citada como um recurso de apoio importante. “Esses [família extensa] são tão importantes quanto a família nuclear, aquela que tá dentro de casa" (P3).

Assim, a família extensa foi apresentada como uma possível fonte de suporte e amparo, sendo vista como "auxílio no cuidado e na criação" dos filhos (P4). Com isso, inferese que a importância da família está relacionada principalmente à sua capacidade de suprir as necessidades físicas e emocionais de seus membros, e não tanto a ter sua configuração 
guiada pelo modelo nuclear como ideal: "A partir do momento que tu consegue ter essa troca de papéis na família nuclear [referindo-se aos papéis de pai, mãe e da família extensa], digamos, tu consegue ter um ambiente mais saudável" (P3).

Em outras palavras, um ambiente familiar saudável pode ser descrito como aquele que não delimita as tarefas familiares a papéis estereotipados de gênero e/ou restringe o cuidado dos filhos e as tarefas familiares às figuras de pai e mãe. Essa capacidade de adaptar a estrutura e a dinâmica das relações familiares conforme as mudanças internas e externas sofridas pelo sistema foi apresentada na literatura por Minuchin (1982), e retomada por Wagner, Tronco e Armani (2011) através do conceito de "flexibilização", uma importante habilidade familiar que denota a saúde do sistema ao ser capaz de modificar suas relações e sua organização ante as situações que é exposta.

Os entrevistados concordaram com as considerações apontadas por Minuchin e Fishman (1990), que colocam a família extensa como um recurso a ser mobilizado para que as funções familiares sejam desempenhadas de maneira eficaz. As famílias "multigeracionais", como denominam os autores, devem ser entendidas, então, como uma alternativa adaptativa poderosa, sendo necessário que se evite olhar para elas tomando como base o modelo nuclear e a tendência de buscar em tal configuração suas problemáticas.

\section{Os papéis parentais}

Considerando-se os papéis desempenhados no sistema familiar, quando questionado sobre as características que definem um pai, P3 apresentou a concepção do pai enquanto figura máxima de respeito e obediência, que provê os recursos financeiros para a sobrevivência da família. Um modelo de paternidade que traz como referência a família tradicional, na qual as funções familiares são delimitadas a partir da divisão sexual (Osorio, 2002). Assim, para esse psicólogo a função de pai é: "Mostrar que a família tá segura, assim, pensando bem como antigamente. [...] É esse ponto de segurança, esse, esse alicerce, essa coisa que firma a família. [...] É essa figura de respeito, de... de provedor de recursos, de segurança" (P3). 
Para os demais entrevistados, o pai foi posto como uma das figuras responsáveis por fornecer condições para o desenvolvimento biopsicossocial dos filhos, ampliando-se o foco do sustento financeiro familiar. Contudo, sem desconsiderá-lo, os participantes deram destaque para uma postura afetiva, de preocupação e envolvimento ativo na educação das crianças:

Eu acho que é dar amor pros seus filhos. É ser um pai presente. Ser um pai que converse muito, que tenha diálogo, que dê carinho, que preserve o vínculo. (P1)

Uma das coisas que eu acho importante pro pai seria afeto. Poder disponibilizar afeto e segurança afetiva. [...] Tu dá condições pra pessoa se desenvolver e é isso... mas eu não sei exatamente como pôr em palavras o que seria essas condições, assim, segurança afetiva e as mínimas condições materiais pra, enfim, viver. [...] Também a questão da educação, de educar os filhos, enfim, de preparar os filhos para o mundo. (P2)

Em comparação ao pai de concepção "patriarcal", as falas dos participantes mostraram conformidade com as considerações de Roudinesco (2003) e Trad (2010) a respeito das modificações dos comportamentos e relações estabelecidas dentro da família, sinalizando uma divisão mais igualitária e flexível entre pais e mães no cuidado dos filhos e no sustento do lar. Ainda, a discrepância identificada entre os participantes na maneira de conceber a paternidade ilustrou a coexistência dos modelos de parentalidade, a saber, os que tendem ao desempenho mais tradicional dos papéis materno e paterno e os que seguem um padrão contemporâneo de papéis mais igualitários (Souza \& Ramires, 2006).

Seguindo uma visão mais igualitária sobre os papéis de pais e mães, a maioria dos psicólogos relatou na entrevista considerar o papel familiar da mãe similar e compartilhado com o do pai, demonstrando haver um entendimento da importância da função parental ser desempenhada de forma conjunta e coerente pelos cuidadores:

Eu acho semelhante e circulando, tipo, não vejo muito porque ter papéis fixos, tipo, pra tal pessoa fazer tal coisa e daí a outra pessoa fazer outra coisa diferente na educação dos filhos. (P2)

Também [semelhante as características atribuídas ao pai]. A gente faz tudo por um filho, né. É dar limite também. (P1) 
A demarcação de limites às crianças, tarefa parental ressaltada por $\mathrm{P} 1$, juntamente ao prover e ao ato de dar afeto, devem ser desempenhados de forma constante e em sintonia pelos cuidadores envolvidos na educação (Cordioli, 1998). Como assinalado por Berthoud e Bergami (1997) e Melo (2012), a partir dessas funções se propicia aos filhos a assimilação dos valores que são transmitidos através das relações familiares e a construção de uma imagem segura de si e do mundo, contribuindo para sua socialização. Segundo Campos (2012), a imposição de limite no meio familiar favorece a inserção dos filhos na vida em sociedade.

Então, eu acho que tanto a mãe, quanto o pai; também essa questão afetiva, de ser carinhoso, de demonstrar que se importa, que se preocupa. Erroneamente a gente acha que a mãe é mais carinhosa, o pai é mais rígido, enfim, mas claro, né, às vezes por ser homem a gente acha assim. (P4)

Ainda sobre a concepção dos psicólogos a respeito do papel de mãe, P3 foi o único dos entrevistados que demonstrou conceber a figura materna mais próxima da definição de desempenho clássico dos papéis de gênero da família tradicional, subordinada ao homem e associada à função de cuidadora (Osorio, 2002).

É quem protege de outra forma. É quem cuida, é quem dá o carinho, assim, é bem aquela família nuclear perfeita, totalmente o que a gente estuda pra não ser, mas é a visão que eu tenho e que eu tento não poluir nas famílias isso. (P3)

Assim, considera-se que o contato com famílias que se configuram e se organizam de modo distinto ao da família na qual o psicólogo foi criado, inclusive as que são atendidas no CRAS, possa estar exercendo influência e modificando a maneira de P3 conceber o que é ser uma família (Souza, 2016).

Com isso, foi possível perceber a maneira que esses profissionais concebem o papel de mãe e de pai, de homem e de mulher, do masculino e do feminino; nos dias atuais e em relação ao desempenho das funções familiares. De modo geral, para esses, não pareceu estar naturalizada a partir do gênero a delimitação da função de prover e de cuidar da família. Entende-se, assim, que cada família, em sua singularidade, encontra sua forma de se organizar e de se relacionar, forma essa que recebe influência tanto de fatores internos a esse sistema (ex. valores familiares, padrões de relação etc.), como de fatores externos (ex. 
fatores ambientais, sociais e econômicos), não sendo possível considerar que exista uma fórmula pronta ou correta de "ser família" (Gomes, 2015). Isso posto, percebeu-se também um olhar crítico dos psicólogos diante de uma expectativa social relacionada à divisão sexual que circula no imaginário social.

Partindo das falas e discussões expostas, pode-se considerar que, de modo geral, os psicólogos apresentaram uma visão de família em consenso com o que a teoria aponta para a "família contemporânea brasileira": união de pessoas que possuem como premissa o vínculo afetivo, a proteção e o desenvolvimento dos seus membros, fonte de solidariedade e compartilhamento de recursos para sobrevivência (IBGE, 2010).

\section{Indicadores de saúde familiar}

Um dos indicadores mais mencionados pelos psicólogos a respeito da saúde familiar foi a capacidade de resolução de conflitos e dificuldades do dia a dia.

[Uma família que não está bem] Acho que é quando não tem uma comunicação. [...] Ela não tem que ser uma família perfeita. Não é uma família sem brigas, ideal, mas é uma família que funcione. (P3)

Que as coisas vão aparecendo no dia a dia, problemas, né, dificuldades vão aparecendo no dia a dia, e a família que está bem, justamente, ela vai conseguir superar, ela vai conseguir conversar sobre isso, resolver isso, achar o melhor caminho. E a que não está bem, com certeza, ela vai se desesperar, ela vai se desestruturar. (P1)

Ao analisar as falas expostas, entendeu-se que os psicólogos consideraram a comunicação um fator essencial para a manutenção da saúde do sistema familiar, visto que através dela a família pode encontrar a solução dos seus conflitos, impedindo que se agravem e abram margem para a violência e ruptura de vínculos. Sobre isso, Cordiolli (1998) pontuou que a capacidade da família de utilizar seus recursos de comunicação verbal e nãoverbal, bem como estimular a expressão de afeto amoroso e crítico para identificar e resolver seus problemas, são fatores essenciais para manter o bom funcionamento do sistema. Da mesma forma, ao estudar famílias desfavorecidas e psicossomáticas, Minuchin 
(1982) apontou a ausência de comunicação entre pais e filhos e a dificuldade na resolução de conflitos como aspectos problemáticos.

Foi interessante perceber a sintonia existente entre essa maneira de compreender um ambiente familiar saudável e os princípios da atuação do SUAS. De acordo com a fala dos participantes, os níveis de dificuldades intrafamiliares correspondem às ações dos serviços da assistência, uma vez que o CRAS se configura como o serviço responsável por auxiliar na promoção de bem-estar e proteção dos sujeitos, prevenindo o agravamento dos conflitos familiares. Já em níveis de conflitos mais extremos, a intervenção fica por conta do Centro de Referência Especializado de Assistência Social (CREAS), que busca oferecer suporte quando a violação dos direitos já está inserida no sistema familiar (Brasil, 2004).

Uma família que não consegue lidar com os conflitos e que, bom, isso vai causar coisas pras pessoas, tipo, deixar o sofrimento e tal. Porque não que não vá ter sofrimento nas crises normais e cotidianas, mas se os conflitos vão sendo resolvidos. [...] Uma família que não consegue resolver seus conflitos, assim, e daí acaba aumentando os conflitos, enfim, gerando violência. (P2)

É quando essa família adoece, digamos, que é quando essa família começa a ter índice de violência, drogadição, alcoolismo, as crianças elas são esquecidas, os idosos [...]. Quando essas pessoas elas são esquecidas, é quando tem uma negligência, quando tem um abandono. (P3)

Para além dos desacordos comuns, reconhece-se que os relacionamentos intrafamiliares podem atingir níveis de dificuldades extremos, podendo desencadear comportamentos marcados pela violência (Peres, 2001) e o rompimento de vínculos, quando a família não consegue encontrar recursos para lidar com os conflitos (Minuchin, Colapinto, \& Minuchin, 1999). Segundo Minuchin, Colapinto e Minuchin (1999), cada sistema possui um limiar invisível estabelecido para as desavenças, evitando que cheguem à expressão de violência e possam ocasionar a ruptura das relações. Violência, aqui, caracterizada por ações prejudiciais à integridade física ou psicológica dos sujeitos (Brasil, 2011).

Adiante na análise, também foi destacada a importância de a família ser capaz de suprir as necessidades básicas (físicas, emocionais e sociais) de seus membros; em outras palavras, conseguir se organizar para suprir as necessidades das crianças, para que seu 
desenvolvimento físico e psíquico se desenrole com êxito. Assim, ressalta-se a relevância de se manter uma dinâmica de corresponsabilidade e construção coletiva na educação das crianças, estabelecendo um ambiente seguro, que estimule o seu desenvolvimento.

Deve estar estruturada. Estruturada no sentido, assim, de cada um saber o seu papel, de cada um respeitar o outro, a vontade do outro. (P5)

Eu acho que uma família que as pessoas estão bem é uma família que consegue funcionar. Que consegue junto decidir sobre uma educação pra essas crianças. [...] Que essas crianças não sofram agressão, que essas crianças sejam saudáveis, que elas entendam o que que é certo, o que que é errado, de acordo com aquela cultura familiar. Que elas estejam num ambiente de educação. (P3)

P5 se referiu à questão da estruturação familiar. De acordo com a revisão teórica realizada e com a aproximação que a presente pesquisa possui com a Teoria Sistêmica Familiar, entende-se que toda e qualquer família possui uma estrutura. Tal estrutura corresponde à maneira de se organizar, dividir os papeis e responsabilidades entre os membros. Dessa forma, quando uma família encontra dificuldades em realizar suas tarefas enquanto sistema, supõe-se que sua estrutura não está sendo funcional e precisa ser remanejada (Cordioli, 1998).

Compreende-se que a palavra "estrutura" tenha sido tomada em suas entrevistas a partir de seu significado e utilização populares. Dessa forma, inferiu-se que, quando os psicólogos indicaram que a família precisa estar estruturada, o sentido que davam era o de um sistema funcional. Segundo Carter e McGoldrick (1995), essa funcionalidade pode ser analisada a partir da clareza das fronteiras e hierarquia estabelecidas entre os subsistemas (conjugal, fraterno etc.) e do êxito na execução das tarefas familiares. Diante disso, alerta-se para o cuidado que se deve ter para não julgar erroneamente as famílias que diferem da configuração nuclear como "famílias desestruturadas", com tom pejorativo.

Uma família estruturada emocionalmente. Eu acho que daí tu vê que as pessoas estão bem. [...] Que conseguem superar problemas, resolver. [...] Que consegue conversar sobre os assuntos e resolver esse, e chorar, e rir. Né? Enfrentar as coisas, eu acho que é uma família bem estruturada. Problemas todos nós temos, né. (P1) 
Ainda sobre as características de uma família que se encontra presa em uma dinâmica que traga prejuízo ao bem-estar de seus membros e que precisa ser amparada, a presença de problemas de saúde também apareceu como um dos fatores que podem favorecer a fragilização dos vínculos familiares e influenciar na dinâmica que vai ser estabelecida.

"Eu acho que daí se desestrutura, assim. Começa pela quebra do respeito [...]. E no caso de saúde eu acho que também desestrutura, porque fragiliza a família como um todo" (P5).

Em acordo com a fala do participante, as questões de saúde, juntamente com a cultura familiar, grupo étnico, religião, origens geográficas e educação formal, também foram postas por Gomes (2015) como fatores que precisam ser levados em consideração ao analisar a qualidade das relações familiares.

\section{Considerações finais}

A partir da análise das entrevistas realizadas, identificou-se que, para os psicólogos entrevistados, o que transforma um grupo de pessoas em uma família é o estabelecimento de uma dinâmica de relações recíprocas pautadas no afeto, no cuidado e na preocupação com o bem-estar dos membros desse sistema, indicando uma visão arejada e não preconceituosa acerca das famílias. Percebe-se que os profissionais apresentaram um discurso pautado no conhecimento teórico e técnico desenvolvido pela psicologia sobre a temática de famílias, sem pautá-lo no senso comum ou em julgamentos morais acerca da família atual.

Os profissionais também citaram o conflito intrafamiliar como elemento intrínseco a essas relações. Com isso, a concepção de família pouco tendeu a uma visão romantizada, sendo reconhecido que nem todos os períodos de convívio são harmônicos. Segundo a literatura, isso pode ser explicado pelo fato da dinâmica familiar ser constantemente influenciada por estressores internos e externos ao sistema, sendo convocada a reorganizar suas regras, relações e papéis. Essa flexibilidade também foi considerada nas entrevistas como um importante fator que auxilia no bem-estar familiar. 
Considerando que o vínculo estabelecido entre os psicólogos e o público alvo das ações do CRAS se alicerça não apenas na técnica profissional, mas também na sua cultura subjetiva, fica o alerta para que os poucos resquícios encontrados de uma concepção de família pautada no modelo patriarcal não contribuam para uma leitura estigmatizada da pobreza, tornando fértil o solo para a adoção de uma postura profissional que culpabiliza as famílias e sujeitos atendidos no CRAS. Mesmo que poucas respostas tenham sido portadoras de um discurso com uma tonalidade conservadora do que é concebido como família, preocupa a forma como tais concepções possam aparecer na atuação cotidiana dos profissionais, com o risco de oferecerem uma leitura estigmatizante das famílias.

Tomando em perspectiva as produções científicas acerca da temática trabalhada, pouco se encontrou a respeito da interlocução entre a Psicologia, o Sistema Único de Assistência Social e a atuação centrada na família. Compreendeu-se a escassez de material em virtude da ainda recente inserção da profissão nesse campo de atuação, mas que se encontra em processo de desenvolvimento. Assim, espera-se que o presente estudo contribua para a aproximação dos psicólogos com as questões políticas e sociais, de modo a inspirar o distanciamento de uma postura alienada da classe e fortalecendo a implicação na luta contra a desigualdade social brasileira.

Considerando a recente inclusão das políticas públicas nas disciplinas das graduações em psicologia, reflexo da inserção do psicólogo no SUAS, a formação continuada parece ser também uma alternativa para sanar as lacunas da formação. Assim, espera-se que esses resultados contribuam para a efetivação de uma atuação sensível, crítica e comprometida socialmente. Ainda, destaca-se a importância do desenvolvimento de um olhar acolhedor e unificado entre os profissionais da equipe do CRAS acerca dos usuários, que pode ser alcançado através do compartilhamento de conhecimento em reuniões de equipe.

Das limitações desse estudo, consideram-se o vínculo de trabalho dos psicólogos participantes com o CRAS (quatro contratados e um concursado em período probatório) e o pouco tempo de atuação no local (máximo um ano) como elementos constituintes do complexo pano de fundo que influenciou os resultados encontrados. Entende-se que a modalidade de vinculação profissional por contrato temporário muitas vezes mobiliza no 
profissional o sentimento de insegurança ante a sua prática, além de poder dificultar a qualificação da prática e a autonomia técnica (Leão, Oliveira, \& Carvalho, 2014). Além disso, a própria situação de pesquisa pode provocar a sensação de obrigatoriedade de participação e inibir o profissional de falar sobre sua atuação, visto que a prefeitura da cidade permitiu a coleta de dados nos serviços. Por fim, levantam-se algumas possibilidades de investigações futuras que venham a complementar os resultados obtidos. Considera-se importante que estudos futuros se empenhem na ampliação dos participantes para outros profissionais que componham a equipe dos CRAS. Além disso, mostra-se essencial conhecer a concepção de família dos próprios usuários do CRAS/SUAS.

\section{Referências}

Arrazola, L. S. D. (1997). O cotidiano sexuado de meninos e meninas em situação de pobreza. In F. R. Madeira (Ed.), Quem mandou nascer mulher? (pp. 347-402). Rio de Janeiro: Record/Rosa dos Tempos.

Bardin, L. (1979). Análise de conteúdo. Lisboa: Edições 70.

Berthoud, C. M. E. \& Bergami, N. B. B. (1997). Família em fase de aquisição. In C. M. O. Cerveny, \& C. M. E. Berthoud (Orgs.), Família e ciclo vital: nossa realidade em pesquisa (pp. 49-73). São Paulo: Casa do Psicólogo.

Brasil, República Federativa do Brasil. Ministério da Saúde. Conselho Nacional de Saúde. (2016) Resolução $N^{\circ} 510$ de 24 de maio de 2016. Normas aplicáveis a pesquisas em Ciências Humanas e Sociais. Brasília, DF: . Conselho Nacional de Saúde. http://conselho.saude.gov.br/resolucoes/2016/reso510.pdf.

Brasil, República Federativa do Brasil. Ministério da Saúde. Secretaria de Vigilância em Saúde. Departamento de Análise de Situação de Saúde. (2011). Viva: instrutivo de notificação de violência doméstica, sexual e outras violências. Brasília, DF: Ministério da Saúde. http://www.saude.pr.gov.br/arquivos/File/Instrutivo_notificacaodeviolencia_versao5_1_f inal21_12_15.pdf 
Brasil, República Federativa do Brasil. Ministério do Desenvolvimento Social e Combate à Fome. Secretaria Nacional de Assistência Social. (2004). Política Nacional de Assistência $\begin{array}{llll}\text { Social. Brasília, } & \text { DF: }\end{array}$ http://www.mds.gov.br/webarquivos/publicacao/assistencia_social/Normativas/PNAS2 004.pdf

Brasil, República Federativa do Brasil. Ministério do Desenvolvimento Social e Combate à Fome. Sistema Único de Assistência Social. Proteção Social Básica. (2009). Orientações técnicas: centro de referência de assistência social. Brasília, DF: MDS. http://www.mds.gov.br/webarquivos/publicacao/assistencia_social/Cadernos/orientaco es_Cras.pdf

Campos, D. C. (2012). Saudade da família no futuro ou o futuro sem família? In M. N. Baptista, \& M. L. Teodoro (Orgs.), Psicologia de família: teoria, avaliação e intervenção (pp. 74-86). Porto Alegre: Artmed.

Carter, B., \& McGoldrick, M. (Orgs.). (1995). As mudanças no ciclo de vida familiar: uma estrutura para a terapia familiar. Porto Alegre: Artes Médicas.

Celia, S. (2013). Parentalidade e pobreza: uma experiência brasileira. In C. Gutfreind, I. L. Celia, N. Beck, \& V. Guerra (Orgs.), A obra de Salvador Celia: empatia, utopia e saúde mental das crianças (pp. 57-71). Porto Alegre: Artmed.

Centro de Referência Técnica em Psicologia e Políticas Públicas (CREPOP). (2008). Referências técnicas para atuação do (a) psicólogo (a) no CRAS/SUAS. Brasília: Conselho Federal de Psicologia.

Conselho Federal de Psicologia \& Conselho Federal de Serviço Social. (2007). Parâmetro para atuação de assistentes sociais e psicólogos (as) na Política de Assistência Social. Brasília, DF: CFP, CFSS.

Conselho Federal de Psicologia. (2000). Resolução No 016 de 24 de dezembro de 2000. Dispõe sobre a realização de pesquisa em Psicologia com seres humanos. Brasília, DF: CFP. http://www.crpsp.org.br/portal/orientacao/resolucoes_cfp/fr_cfp_016-00.aspx.

Cordioli, A. V. (1998). Psicoterapias: abordagens atuais. Porto Alegre: Artes Médicas.

Coutinho, V. R., \& Merigo, J. (2010). A atuação do psicólogo na Política Nacional de Assistência Social e especialmente nos Centros de Referência da Assistência Social 
[Trabalho de Conclusão de Pós-graduação em Políticas Públicas e Demandas Familiares, Universidade do Sul de Santa Catarina].

Gomes, D. M. (2015). Família(s) [entrevista concedida]. Revista Entre linhas, 69, 12-15.

lamamoto, M. (2007). A produção teórica brasileira sobre os fundamentos do trabalho do Assistente social. In M. Iamamoto, Serviço Social em tempo de capital fetiche: capital financeiro, trabalho e questão social (pp. 209-333). São Paulo: Cortez.

Instituto Brasileiro de Geografia e Estatística [IBGE]. (2010). Censo demográfico 2010: famílias e domicílios. Rio de Janeiro: IBGE.

Kehl, M. R. (2003). Em defesa da família tentacular. In: G. C. GROENINGA, \& R. C. PEREIRA (Coord.). Direito de família e psicanálise (pp. 13-176). Rio de Janeiro: Imago.

Koller, M. S. H., Antoni, C. \&Carpena, M. E. F. (2012). Famílias de crianças em situação de vulnerabilidade social. In M. N. Baptista \& M. L. M. Teodoro (Orgs.), Psicologia de família: teoria, avaliação e intervenção (pp. 156-165). Porto Alegre: Artmed.

Leão, S. M., Oliveira, I. M. F. F., \& Carvalho, D. B. (2014). O psicólogo no campo do bemestar social: atuação junto às famílias e indivíduos em situação de vulnerabilidade e risco social no CRAS. Estudos e pesquisa em psicologia, 14(1), 264-289. http:/ / pepsic.bvsalud.org/pdf/epp/v14n1/v14n1a15.pdf

Melo, J. D. N. (2012). A concepção de família na política nacional de assistência social brasileira: no foco da criminalização da pobreza. Memorias: Revista Digital de Historia y Arqueología desde el Caribe, 17, 102-134. https: / / www.redalyc.org/articulo.oa?id $=855 / 85524080005$

Meyer, D. E. (2003). Gênero e educação: teoria e política. In G. L. Louro, J. F. Nekel, \& S.V. Goellner (Eds.), Corpo, gênero e sexualidade: um debate contemporâneo na educação (pp. 9-27). Petrópolis: Vozes.

Minayo, M. C. S. (Org.). (2013). Pesquisa Social: teoria, método e criatividade. Petrópolis: Vozes.

Minuchin, S. (1982). Famílias: funcionamento e tratamento. Porto Alegre: Artes Médicas. 
Minuchin, P., Colapinto, J., \& Minuchin, S. (1999). Trabalhando com famílias pobres. Porto Alegre: Artes Médicas Sul.

Minuchin, S., \& Fishman, H. C. (1990). Planejamento. In S. Minuchin, \& H. C. Fishman, Técnicas de terapia familiar (pp. 58-71). Porto Alegre: Artes Médicas.

Moreira, M. I. C. (2013). Novos rumos para o trabalho com famílias. São Paulo: Associação dos Pesquisadores de Núcleos de Estudos e Pesquisas sobre a Criança e o Adolescente.

Osorio, L. C. (2002). Casais e famílias: uma visão contemporânea. Porto Alegre: Artmed.

Peres, V. L. A. (2001). Concepções de família em população de periferia urbana. In S. M. G. Sousa (Org.), Infância, adolescência e família (pp. 217-230). Goiânia: Cânone Editorial.

Roudinesco, E. (2003). A família em desordem. Rio de Janeiro: Jorge Zahar.

Santos, L. N. (2014). A psicologia na assistência social: convivendo com a desigualdade. São Paulo: Cortez.

Sarti, C. (2010). Famílias enredadas. In A. R. Acosta, \& J. A. F. Vitale (Orgs.), Famílias, redes, laços e políticas públicas (pp. 31-48). São Paulo: Cortez/PUC-SP.

Senra, C. M. G. (2014). A psicologia e o suas: desvelando a atuação do psicólogo no CRAS. In R. C. Ramagnoli, \& M. I. C. Moreira (Orgs.), O sistema único de assistência social - SUAS: a articulação entre a psicologia e o serviço social no campo da proteção social, seus desafios e perspectivas (pp. 13-27). Curitiba: CRV.

Senra, C. M. G., \& Guzzo, R. S. L. (2012). Assistência social e psicologia: sobre as tensões e conflitos do psicólogo no cotidiano do serviço público. Psicologia \& Sociedade, 24(2), 293-299. http://doi.org/10.1590/S0102-71822012000200006

Settles, B. H. (1999). Definitions of the Family. Marriage \& Family review, 28(3), 209- 224.

Souza, J. (2016). Crack e exclusão social. Brasília: Ministério da Justiça e Cidadania, Secretaria Nacional de Política sobre Drogas.

Souza, R. M., \& Ramires, V. R. (2006). Amor, casamento, família, divórcio... e depois, segundo as crianças. São Paulo: Summus.

Trad, L. A. D. (2010). A família e suas mutações: subsídios ao campo da saúde. In L. A. D. Trad (Org.), Família contemporânea e saúde: significados, práticas e políticas públicas (pp. 27-50). Rio de Janeiro: Editora Fiocruz. 
Wagner, A., Tronco, C., \& Armani, A. (2011). Os desafios da família contemporânea: revisando conceitos. In A. Wagner (Org.), Desafios psicossociais da família contemporânea: pesquisas e reflexões (pp. 19-35). Porto Alegre: Artmed.

Recebido em: $24 / 7 / 2018$

Aprovado em: 26/4/2019 